\title{
The volume profile method and its theoretical connection with microeconomic theory as the main premise of its application
}

\author{
Jan Chutka ${ }^{1, *}$ \\ ${ }^{1}$ University of Zilina, Faculty of Operation and Economics of Transport and Communications, \\ Univerzitna 1, 01026 Zilina, Slovakia
}

\begin{abstract}
Research background: This article was conceived as a very valuable basis and the result of theoretical research in the field of microeconomics with a specific application. Specifically, in the article we tried to accurately describe the logic and predictive weight of the Volume profile method with reference to the exact descriptions of the functioning of the market mechanism.

Purpose of the article: The aim of our paper is to describe in detail and identify the microeconomic foundations of the Volume Profile prediction tool.

Methods: In the first chapter of the article, we described in detail the investigated method of volume profile. Subsequently, we described its logic, functions and detailed calculation as well as its use. We continued with a description of the basic interactions between supply and demand, as well as a description of the market mechanism.

Findings \& Value added: The result was an accurate identification and description of the connection between the operation of the investigated prediction method and its microeconomic basis.
\end{abstract}

Keywords: volume profile; supply; demand

JEL Classification: $D 00 ; G 15 ; G 17$

\footnotetext{
${ }^{*}$ Corresponding author: chutka.jan@gmail.com
} 


\section{Introduction}

In today's world, it is common practice to offer individual traders and investors in the financial markets a wide range of prediction tools. Most of them are simple and user-friendly (Kudlac et al., 2017). However, few of these methods have their foundations in scientific procedures and in economic laws. In our paper, we will discuss in detail the issue of using the Volume Profile method and identify its real microeconomic fundamentals.

\section{Methods}

\subsection{Volume profile}

Volume Profile is an advanced chart study that shows trading activity over a specified period of time at specified price levels. This technical analysis tool plots a histogram on a graph to reveal dominant or significant price levels based on volume. The volume profile basically takes the total volume traded at a specific price level during a given period of time and then easily makes this information visible to the trader by graphical expression directly in the price chart of the analyzed financial instrument. The creator of the Volume Profile method is considered to be J. Peter Steidlmeyer, who already in 1958 began to deal with the idea of using the Gaussian curve in the field of financial market trading.

During the study of the Gaussian curve, Staidlmeyer realized a great similarity with the distribution of trading volume in individual time periods. Steidlmayer realized that in the market it is possible to group trends statistically to create a Gaussian curve. He came up with the idea that the Gaussian curve could be used to represent the arrangement of behavior around price. The first standard deviation (middle of the bell curve), where most of the activity takes place $(68 \%)$, would be value, while the second and third deviations would measure price from value. This idea later led him to create a theory of the auction process in the financial markets and subsequently to create a market profile method, an offshoot of which is the Volume profile we mentioned. (Chicago Board of Trade, 1996; (Chovancova et al., 2016))

Typical significance levels calculated using the volume profile method:

- Point of control (POC) - the price level in the time period with the highest traded volume.

- High profile (HP) - the highest achieved price level during the specified time period.

- Low profile (LP) - the lowest achieved price level during the specified time period.

- Value Area (VA) - The range of price levels at which a specified percentage of the entire volume was traded during a given period. This percentage is usually set at $70 \%$, but is at the discretion of the trader.

- Value Area High (VAH) - the highest price level in the value area.

- Value Area Low (VAL) - the lowest price level in the value area.

To calculate the Volume profile method:

1. The first step in calculating the volume profile levels is to determine the time and price frame for which we will calculate the individual levels.

2. The second step is to identify the structure of the total traded volume in our predetermined price and time interval.

3. The third step is the identification of the value area (VA), namely the determination of the $\%$ share of the total number of trades in a given interval. The most commonly used value is $70 \%$, which is derived from the first standard deviation in both directions in the case of the Gaoss curve.

4. The next step is to identify the price with the highest realized volume of trades (POC). This price will serve as the zero point from which the individual deviations will apply. 
5. The following is the identification of the price range corresponding to $70 \%$ of the share of all executed trades. We apply a $35 \%$ band in both directions and this area is just the value area (VA).

6. The highest (marginal) price of the VA margin is thus identified as Value Area High (VAH) - the highest price level in the value range.

7. The lowest (marginal) price of the VA margin is thus identified as Value Area Low (VAL) - the lowest price level in the value area.

8. The price range belonging to the band between the high profile (the highest achieved price level during the specified time period) and the VAH defines the area of positive price extremes.

9. The price range belonging to the band between the low profile (the lowest achieved price level during the specified time period) and VAL defines the area of negative price extremes.

\subsection{Microeconomics foundation of Supply and Demand}

Due to their complexity, size and trading volume, financial markets can be considered the closest example of the functioning of a market mechanism. Unlike the command economy, where the redistribution of production factors and resources is decided by the government, the market system is just such a system of economic organization in which the three basic economic issues are addressed not by central planning but exclusively through interaction between producers and consumers - market mechanism (Oláh et al., 2019). It represents a set of relationships and processes that help the coordination of free individual economic entities in the allocation of production factors, prices of goods and the like, through the transmission of information by the price system (László and Csete, 2008; Siekelova et al., 2021). The market mechanism works automatically depending on the level of demand, supply and the effect of price (Lisy, 2016; Lăzăroiu, 2020).

The basic tasks of the market include solving a triad of economic issues:

1. WHAT is to be produced and in what quantities.

2. HOW the goods are to be produced (determined by competition between producers).

3. FOR WHOM to produce goods and goods.

When we start talking about the market, as we have already said, it can be defined as a place of mutual conflict / interaction between demand and supply for goods and services. Therefore, it is very important to describe and define this mutual interaction of supply and demand in detail. Demand can be characterized as the amount of goods that buyers are willing and able to buy depending on its current price. Demand (D) represents the interdependence between the quantity of goods and services required $(\mathrm{Q})$ and their price $(\mathrm{P})$. Thus, while maintaining the level of demand, we can say that the lower the price of the goods, the larger the required quantity of this good and vice versa. It is important to be aware of the difference between demand and quantity. Demand expresses the behavior of buyers with respect to price (expressed by the demand curve) and the term required quantity expresses the relationship of a specific demand to a certain price of the good, which is only one quantity (Q) (Lisy, 2016). The other side of potential trade is supply (S). The offer is made up of producers and sellers (companies, entrepreneurs) who decide on the basis of their own goal and discretion, what they will produce and in what quantity. The offer therefore represents the total quantity of goods and services which they sell willing and able to sell depending on the current price of the goods in question. The supply curve expresses the relationship between the price and the quantity offered, which producers are willing to produce the goods and then sell. (Paskaleva \& Stoykova, 2021; Popescu, 2020; Baumol, 2011; Rozanova, 2011; Allen, 2000; Rochet and Fraysse 1997; Rader, 1967). 
In the market, therefore, the interaction between supply and demand. Each of these parties has its own interests in the market. Thus, a trade can take place on the market if it meets the interests of demand and supply, and thus the buyer is willing to find the purchase amount in question for a specific quantity in a given quality, which is affordable at a given price. Thus, we call market equilibrium a situation in which the market participants forming the markets do not in any way take over their buying or selling behavior. It is a natural feature of the market that is evolving and striving to reach this equilibrium (Rubinstein and Clark, 2017). Market equilibrium is described as the intersection of supply and demand curves (equilibrium), which gives us a specific price (equilibrium price $\mathrm{Pe}$ ) and a specific quantity (equilibrium quantity Qe) for which there is neither a surplus nor a shortage of goods or services. It is necessary to note that this phenomenon in the real market occurs very rarely, as a result of a huge number of constantly changing influencing factors. There are many current market situations in deficit and surplus. We define these market conditions as unbalanced. (Musa et al., 2021; Nguyen et al., 2020)

We speak about deficit in such a case if our supply suddenly decreases or the demand for a given commodity suddenly increases (demand exceeds supply, $\mathrm{D}>\mathrm{S}$ ). This condition is described as a condition where buyers have purchased all available goods on the market at a given price. Supply responds to this by increasing the price of the goods on offer, which results in a weakening of demand for this good. This mechanism is repeated until a new market equilibrium is established in the market with an equilibrium price and an equilibrium quantity. From the above, we can conclude that the market deficit always results in an increase in the price of goods. We speak of a surplus when supply suddenly increases in the market or demand falls (Supply exceeds demand, S $>$ D). This market situation is described as a situation where all buyers have bought a given quantity of goods at a given price and there is no one to buy these goods under the given conditions. In such a case, manufacturers respond by reducing the cost of production to motivate demand for further purchases (Majercak et al., 2013). This cycle of declining prices and rising demand-side purchases is repeated until a market equilibrium is established in the market with an equilibrium price and an equilibrium quantity. We can state that the result of the surplus is always a decrease in the price of the good.

\section{Results}

These microeconomic theories are very valuable in the analysis of financial markets. When we realize that financial markets are approaching us to a theoretical market mechanism, we can say that the interaction between market participants is very similar to that of the theoretical microeconomic model.

When we begin to analyze the Volume Profile indicator, we find that it is this indicator that analyzes the basic information needed to identify the equilibrium price, and that is the trading volume. Many traders focus only on the analysis of the price of a financial instrument, but the price as such is only the result of the interaction between supply and demand, and therefore if we want to successfully predict future price developments, we must focus on studying trade volume. The trading volume offers us two basic, but very valuable information:

- Price levels at which the trade volume is relatively low can be considered as places of market imbalance and thus places of deficit or surplus.

- The price level with the highest trading volume within a certain time and price range is an equilibrium price.

Thus, if we have identified an equilibrium price in the market and we know that the market tends to return to the original market equilibrium or create a new market equilibrium, we can identify price levels that are advantageous for buying or selling an asset. However, it 
should be borne in mind that a large number of determinants affect the market. If the market imbalance has occurred through a change in any non-price factor (macroeconomic indicators, policy statements, natural disasters, etc.) we can expect the market equilibrium to be restored to a new price level. However, if the balance is disturbed only due to a change in the price factor, the balance will be restored to its original level. (Costa et al., 2020; Gaspareniene \& Remeikiene, 2020)

Distinguishing changes in these types of influencing factors can be a difficult problem in some cases. However, they can be largely identified on the basis of the characteristics of the price changes they cause. A characteristic phenomenon of the change in the price factor is that the price oscillates around the equilibrium price, to which it still tends to return. Based on the theory of technical analysis, we can say that such a character corresponds to the socalled a trendless situation where the price stays in a certain price range for a certain time. On the contrary, characteristic changes in the non-price factor are trend situations where the equilibrium price is always formed at new levels. The volume profile method is focused on such an analysis of the business volume of financial instruments. (Ginevicius et al., 2021; Hyers, 2020)

Based on the calculation procedure described above, this method graphically shows us the identified levels. The interpretation of these levels from a microeconomic point of view is as follows:

- POC - equilibrium price of a given price and time interval

- VP - maximum price of the interval

- NP - minimum interval price

- VA - the area of value, close to the equilibrium price and the minimum deficit or surplus of the asset

- VAH - an area of large imbalance, we identify a high surplus

- VAL - an area of large imbalance, we identify a high deficit

Therefore, if we look at the structure of individual price areas from the point of view of their connection with the trading volume, the data obtained in this way and their interpretations can be used in a simple way to predict future price developments.

\section{Discussion}

Based on the above characteristics of the Volume Profile method and the description of basic microeconomic laws, we can state with certainty that this method can clearly refer to the relationship and effect of supply and demand and to the market mechanism itself. In our opinion, it is one of the few prediction methods that is based on real economic processes and regularities and does not refer only to the basic rule of technical analysis that history repeats itself.

\section{Conclusion}

The aim of this article was to find the scientific basis for the operation of the Volume profile prediction method. In the first chapter of our article, we dealt with a detailed description of this method and its individual aspects and method of calculation. Subsequently, we continued with a detailed description of the functioning of the basic interaction between supply and demand and the process of restoring market equilibrium. We further pointed out and identified the links between this prediction method and the market mechanism based on the interaction of supply and demand. We believe that our contribution will be valuable in the field of research on this issue. 


\section{References}

1. Allen, B. (2000). The future of microeconomic theory. Journal of economic perspectives, 14(1), 143-150.

2. Baumol, W. J. (2011). Formal Microeconomic Structure for Innovative Entrepreneurship Theory. Entrepreneurship research journal, 1(1).

3. Chicago Board of Trade (1996). A Six-part Study Guide To Market Profile. Market Profile.

4. Chovancova, B. et al. (2006). Financial market: instruments, transactions, institutions. 1st ed. Bratislava: IURA EDITION.

5. Costa J., Rodrigues A. C., \& Ferreira M. R. (2020). Organizational culture in social economy organizations. Economics and Sociology, 13(3), 155-170

6. Gaspareniene, L., \& Remeikiene, R. (2020). Arima model for predicting the development of the price of gold: European approach. Ekonomicko-manazerske spectrum, 14(1), 87-96.

7. Ginevicius, R., Kliestik, T., Stasiukynas, A., \& Suhajda, K. (2021). The Impact of National Economic Development on the Shadow Economy. Journal of Competitiveness 12(4), 39-55.

8. Hyers, D. (2020). Big Data-driven Decision-Making Processes, Industry 4.0 Wireless Networks, and Digitized Mass Production in Cyber-Physical System-based Smart Factories. Economics, Management, and Financial Markets, 15(4), 19-28.

9. Kudlac, S., Majercak, J., \& Majercak, P. (2017). Comparison of different variants of logistics chain with the use of air transport using the software application. In Proceedings of 6th International Conference on Air Transport (INAIR) (pp. 45-50).

10. László, V., \& Csete, M. (2008). Sustainable consumption. In Michel, Carmona; János, Szlávik; Éva, Zám (Eds.) Periodica Oeconomica: regional development and competitiveness: studies on economic sciences of University of Paris-Sorbonne IV and Eszterházy Károly College (pp 93-103). EKF Líceum Kiadó.

11. Lăzăroiu, G., Kovacova, M., Siekelova, A., \& Vrbka, J. (2020). Addictive Behavior of Problematic Smartphone Users: The Relationship between Depression, Anxiety, and Stress. Review of Contemporary Philosophy, 19, 50-56.

12. Lisy, J. (2016). Economics. Wolters Kluwer.

13. Majercak, P., Klestik, T., Masarova, G., Buc, D., \& Majercakova E. (2013). System approach of logistic costs optimization solution in supply chain. Nase More, 60(5-6), 9598.

14. Musa, H., Musova, Z., Natorin, V., Lazaroiu, G., \& Martin Boda, M. (2021). Comparison of factors influencing liquidity of European Islamic and conventional banks. Oeconomia Copernicana, 12(2), 375-398.

15. Nguyen, C. P., Schinckus, C., Thanh, S. D., \& Chong, F. H. L. (2020). Institutions, economic openness and credit cycles: An international evidence. Journal of International Studies, 13(4), 229-247.

16. Oláh, J., Popp, J., Máté, D., \& Ardhi Hidayat, Y. (2019). Market structure and concentration ratio: evidence of IT companies in Hungary. Forum Scientiae Oeconomia, 7(3), 7-18.

17. Paskaleva, M., \& Stoykova, A. (2021). Globalization effects on contagion risks in financial markets. Ekonomicko-manazerske spektrum, 15(1), 38-54. 
18. Popescu, G. H., Zvarikova, K., Machova, V., \& Mihai, E. A. (2020). Industrial Big Data, Automated Production Systems, and Internet of Things Sensing Networks in CyberPhysical System-based Manufacturing. Journal of Self-Governance and Management Economics 8(3), 30-36.

19. Rader, T. (1967). Microeconomic theory. American economic review, 57(3), 604-608.

20. Rochet, J. C. \& Fraysse, J. (1997). Microeconomic theory. Economica, 64(256), 703704.

21. Rozanova, N. M. (2011). Innovative methods in studying microeconomic theory. Terra Econoimcus, 9(2), 124-133.

22. Rubinstein, R., \& Clark, T. T. (2017). "Equilibrium" and "non-equilibrium" turbulence. Theoretical and applied mechanics letters, 7(5), 301-305.

23. Siekelova, A., Belas, J., Podhorska, I., Durana, P. (2021). Accrual-based earnings management: a case study in V4 focusing on mining and quarrying sector. Acta Montanastica, Slovaca, 26(1), 70-83. 